\title{
Phosphorylated tau in cerebrospinal fluid as a marker for Creutzfeldt-Jakob disease
}

\author{
B Van Everbroeck, A J E Green, E Vanmechelen, H Vanderstichele, P Pals, \\ R Sanchez-Valle, N Cuadrado Corrales, J-J Martin, P Cras
}

J Neurol Neurosurg Psychiatry 2002;73:79-82

Objective: To determine the concentrations of microtubule associated protein tau and multiple phosphorylated tau epitopes in the cerebrospinal fluid of patients with sporadic Creutzfeldt-Jakob disease (sCJD), dementias, and controls, in order to evaluate their diagnostic use and clinical relevance.

Methods: The CSF concentrations of total tau and phosphorylated tau at epitope 181 were determined by enzyme linked immunosorbent assay in 66 definite and nine probable sCJD patients, and in 97 controls. Other phosphorylated tau epitopes were investigated by western blot.

Results: In the sCJD population, determination of 14-3-3 protein and total tau protein concentrations was of the highest diagnostic value, with a sensitivity of $96 \%$ and $92 \%$, respectively, and a specificity of $94 \%$ and $97 \%$. Two distinct subgroups could be identified among the $75 \mathrm{sCJD}$ patients based on the detection of phosphorylated tau at threonine 181 and serines 199, 202, and 404. A high phosphorylated tau concentration was clinically correlated with a significantly shorter disease duration, early onset of akinetic mutism, and a higher rate of typical EEGs ( $p<0.05)$. Conclusions: Although the determination of phosphorylated tau levels cannot be used as a diagnostic biomarker, it may prove useful for estimating the prognosis of an sCJD patient. These experiments reconfirm that sCJD is a disease with a complex pathology.

C reutzfeldt-Jakob disease (CJD) is a rapidly progressive and ultimately fatal disorder thought to be caused by prions. ${ }^{1}$ At present, a definite diagnosis can only be made at necropsy by neuropathological examination of brain tissue. ${ }^{2}$ The most common form of CJD is the sporadic type (SCJD), with an incidence of $1 / 10^{6}$ inhabitants per year, accounting for $85 \%$ of all known CJD patients. The polymorphism at codon 129 of the prion protein gene (PRNP129) is known to modulate the clinical characteristics and neuropathological phenotype. ${ }^{3}$ PRNP129 encodes for either a methionine $(\mathrm{M})$ or a valine $(\mathrm{V})$. The prion glycosylation pattern (PrP type) determined by western blot analysis shows two different forms. These data serve as the basis for the classification of SCJD into seven subgroups: MM1, MM2ataxic, MM2-thalamic, MV1, MV2, VV1, and VV2. ${ }^{3}$

Cerebrospinal fluid (CSF) contains several proteins that can aid in the clinical diagnosis of SCJD. Immunodetection studies of 14-3-3 protein $^{4}$ and tau protein ${ }^{5}$ have suggested that these are sensitive and specific biomarkers. ${ }^{6}$ On the other hand, normal or raised levels of full length CSF $\beta$ amyloid $\left(A \beta_{1-42}\right)$ have been found in patients suffering from neurological disorders that clinically resemble CJD and yield a positive 14-3-3 or tau result, in contrast to the decreased levels of $A \beta_{1-42}$ found in sCJD patients. ${ }^{78}$
Tau protein and its phosphorylated form are known to be involved in many neurodegenerative disorders. For instance, hyperphosphorylated tau is the most important subunit of neurofibrillary tangles. Finally, in most Alzheimer and sCJD patients, an increased concentration of total CSF tau protein has been reported. ${ }^{589}$

In this study, we investigated whether a new ELISA technique ${ }^{10}$ to measure phosphorylated tau at epitope 181 in CSF could be a sensitive and specific biomarker for sCJD. Further investigations into possible associations between phosphorylated tau levels and the clinical phenotype, genotype, and other biochemical markers in SCJD were also carried out to examine the possible role of tau phosphorylation in CJD disease pathogenesis.

\section{METHODS}

CSF was studied in the following patients: 75 with sCJD (mean (SD) age, 64 (8) years); 34 with Alzheimer's disease (72 (8) years); 33 with other dementia (69 (6) years); and 30 controls (58 (12) years). The other dementia group included vascular dementia $(n=14)$, frontal lobe dementia $(n=12)$, and dementia with Lewy bodies $(n=7)$. The control group included cases of viral encephalitis $(n=9)$, Guillain-Barré syndrome $(\mathrm{n}=3)$, dizziness $(\mathrm{n}=2)$, multiple sclerosis $(n=7)$, polyradiculopathy $(n=4)$, and stroke $(n=5)$. Diagnosis was always made according to classical criteria. ${ }^{11}$

The CSF concentrations of 14-3-3 protein and $A \beta_{1-42}$ were determined as previously described. ${ }^{8}$ Tau protein levels were measured in duplicate by an enzyme linked immunosorbent assay (ELISA) (Innotest hTAU-Ag, Innogenetics, Ghent, Belgium). ${ }^{12}$ A value of $1350 \mathrm{pg} / \mathrm{ml}$ was used as the cut off for a positive test. The concentration of tau phosphorylated at threonine 181 (pl81T phospho-tau) was measured in duplicate using the research version of the Innotest Phospho-Tau ${ }_{181}$ assay. ${ }^{10}$ For standardisation, a phosphorylated synthetic peptide was used in this test. As the determination of total tau uses recombinant tau as standard with a calculated molecular weight of 41063 $\mathrm{kDa}$, it was possible to convert $\mathrm{pg} / \mathrm{ml}$ to $\mathrm{pM}$. The use of these different standards and antibodies in the detection of tau and phospho-tau has resulted, both in this study and in previous work, ${ }^{10}$ in seemingly higher concentrations of phospho-tau than tau when comparing the results in a single patient. ${ }^{10}$ This effect has no direct influence on the evaluation of the results.

Both monoclonal mouse antibodies AT180 (threonine 231235 ) and AT270 (threonine 181, Innogenetics Inc) and rabbit polyclonal antibodies 44-768 (serine 199-202), 44-738 (threonine 205), 44-746 (threonine 231), 44-7580 (serine 404, Biosource Inc, Cammarillo, California, USA) were used in for the determination of phospho-tau in CSF, according to the manufacturer's instructions and using an identical standard in all experiments. The resulting signal was measured and quantified using a Kodak image station 440 and accompanying software. These measurements were used to calculate the ratio of each signal to the standard, while the results were expressed as arbitrary units (AU). 
Table 1 Comparison of the two Creutzfeldt-Jakob disease subgroups, $\mathrm{CJD}_{\text {high }}$ and $\mathrm{CJD}_{\text {low }}$

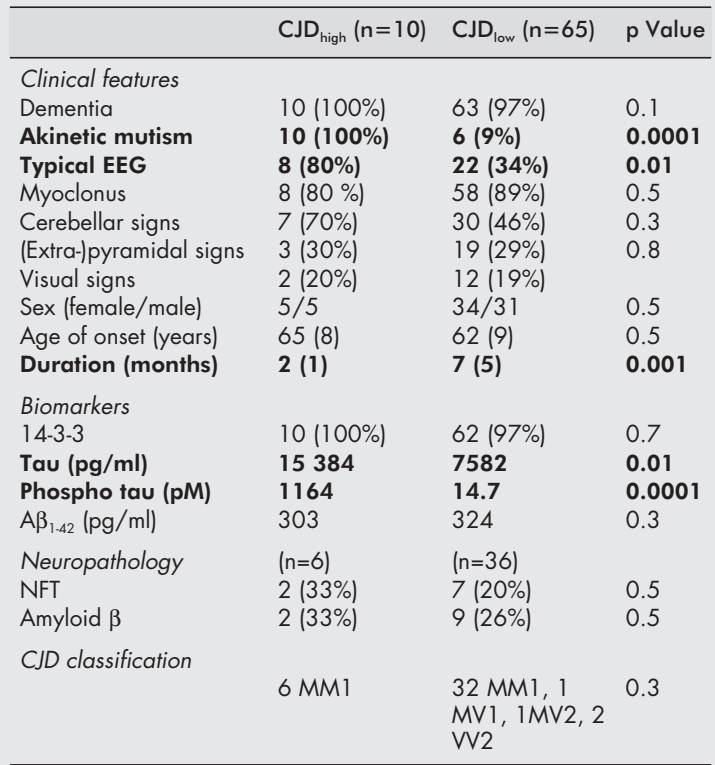

Values are $n(\%)$ or mean (SD).

In the upper part a comparison is made between the clinical features and biomarkers. In the lower part the neuropathological features and CJD classification is compared in patients from whom frozen tissue was available $\left(6 \mathrm{CJD}_{\text {high, }} 35 \mathrm{CJD}_{\text {low }}\right)$. The $\mathrm{p}$ values were calculated using Fisher's exact test except for duration and age of onset (Mann-Whitney $U$ test). Significant values are indicated in bold.

When formalin fixed, paraffin embedded brain tissue was available, neurofibrillary tangles, prion deposition, and amyloid $\beta$ plaques were detected immunohistochemically using AT8 (Innogenetics Inc), ${ }^{13}$ 3F4 (Senetec, St Louis, Missouri, USA), and 4G8 (Senetec) monoclonal antibodies, respectively. The prion protein codon 129 polymorphism and the prion protein strain were determined as described previously. ${ }^{14}$

\section{Statistics}

For all statistical analyses, a cut off probability $(p)$ value of 0.05 was used to determine statistical significance. The results of the ELISA and western blot determinations were examined using the Kolmogorov-Smirnov test (InStat software package), which showed that the results obtained did not have a normal distribution $(\mathrm{p}<0.05)$. Therefore, all results were expressed as medians and centiles, and all analyses were performed using the Mann-Whitney U test. The correlation between groups was calculated using the Pearson product moment coefficient of correlation. The analysis of the different features between the two CJD subgroups was done using Fisher's exact test.

\section{RESULTS}

In SCJD patients, $14-3-3$ and the total tau concentration resulted in the highest sensitivity and specificity. Positive 14-3-3 results were identified in 72 cases of sCJD, one of Alzheimer's disease, two with other dementias, and three controls. Positive tau results (> $1350 \mathrm{pg} / \mathrm{ml})$ were identified in 69 cases of SCJD, one with other dementia, and two controls. Determination of the median concentration of $\mathrm{A} \beta_{1-42}$ (SCJD, 313 pg/ml; Alzheimer's disease, 259 pg/ml; other dementias, 309 $\mathrm{pg} / \mathrm{ml}$; and controls, $360 \mathrm{pg} / \mathrm{ml}$ ) and the median concentration of pl81T phospho-tau (sCJD, 18.7 pM; Alzheimer's disease, $13.6 \mathrm{pM}$; other dementias, $7.3 \mathrm{pM}$; and controls, $7.2 \mathrm{pM}$ ) showed that these tests were not useful for diagnosis.

Based on the concentration of pl81T phospho-tau, two subgroups in the SCJD population could be identified (table 1). High p181T phospho-tau levels were found among SCJD

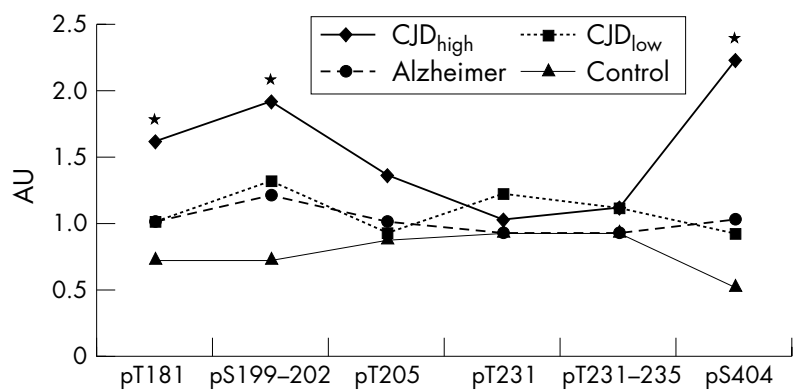

Figure 1 Graphic representation of the determination of phosphorylated tau epitopes in arbitrary units (AU) in the $\mathrm{SCJD}_{\text {low' }}$ $s C{ }_{\text {high }}$, Alzheimer, and control populations. Significant differences are indicated by an asterisk.

patients at all four centres. Upon investigating the clinical features of the two SCJD subgroups, akinetic mutism and a typical EEG were significantly more common in the $\mathrm{sCJD}_{\text {high }}$ subgroup (table 1) than in the $\mathrm{SCJD}_{\text {low }}$ subgroup. Furthermore, disease duration was found to be significantly shorter in the $\mathrm{sCJD}_{\text {high }}$ patients, although no difference was observed with respect to the age of onset (table 1). Possible differences between the two SCJD groups were further analysed (table 1). The $\mathrm{sCJD}_{\text {low }}$ group was found to have significantly lower tau levels than the $\mathrm{SCJD}_{\text {high }}$ subgroup. No difference was found between the two CJD subgroups with respect to 14-3-3 protein and median $A \beta_{1-42}$ concentration (table 1) Finally, we identified patients with or without neurofibrillary tangles and amyloid $\beta$ plaques in both subgroups (table 1). No difference was observed when comparing the neuropathological lesions between the patients formerly classified as MMl patients who were found to be either $\mathrm{sCJD}_{\text {high }}$ or $\mathrm{sCJD}_{\text {low }}$ (table 1).

The analysis of phospho-tau epitopes by immunoblot showed an increased signal for $\mathrm{SCJD}_{\text {high }}$ in some but not all investigated epitopes (fig 1). A significant difference was observed between the $\mathrm{sCJD}_{\text {high }}$ group and all other groups

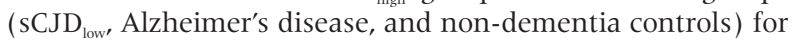
the pT181, pS199-202, and pS404 phospho tau epitopes.

\section{DISCUSSION}

We investigated the concentration of tau and phospho tau in CSF from sCJD and control patients using ELISA and western blot. Two significantly different $\mathrm{SCJD}$ subgroups $\left(\mathrm{sCJD}_{\text {high }}\right.$ and $\mathrm{sCJD}_{\text {low }}$ ) were identified, based on their pl81T phospho-tau concentrations. The $\mathrm{SCJD}_{\text {high }}$ subgroup was characterised by an extremely high concentration of pl81T phospho-tau compared with the $\mathrm{sCJD}_{\text {low }}$ and controls. All sCJD high patients were associated with early akinetic mutism and short disease duration (maximum four months).

The $\mathrm{sCJD}_{\text {high }}$ group showed increased values of certain phospho-tau epitopes-independent of all known disease modifiers but associated with duration of the disease-pointing to a difference in the rate of disease progression. In these "acute" CJD cases neurodegeneration must progress at an increased rate, releasing both tau and phospho-tau in the extracellular space. We hypothesise that in $\mathrm{sCJD}_{\text {high }}$ patients, oxidative stress activates the specific kinases, which results in increased levels of phospho-tau. These pathways might lead to the additional (extra-)cellular phosphorylation of tau, retrieved in the CSF. In our series, only the epitopes pT181, pS199-202, and pS404 were found to be significantly hyperphosphorylated. Previous experiments have shown that epitope specific phosphorylation is induced by certain kinases, ${ }^{15}$ and the glycogen synthase kinase $3 \beta$ specifically phosphorylates the epitopes found in our study. ${ }^{16}$ Conversely, reduced activity of phosphatases or greater resistance to dephosphorylation could also contribute to the observed effect. Whether the difference in 
phosphorylation reflects mainly kinase or mainly phosphatase activity and whether it plays a physiologically significant role must be addressed in future studies.

Although the results we obtained in this study indicate that determination of the pl81T phospho-tau concentration cannot be employed as a diagnostic biomarker, it could be useful for estimating prognosis (suspected disease duration) of an SCJD patient. For use in a clinical setting, however, the test validity should be examined prospectively. Finally, the determination of the pl81T phospho-tau concentration could conceivably be used in future clinical trials to measure the effect of a drug on disease progression.

\section{ACKNOWLEDGEMENTS}

We thank all physicians who sent us the CSF samples and clinical information on suspected CJD patients and control cases. We are also grateful to Karen De Vreese and Annelies De Brauwer (Innogenetics, Ghent, Belgium) for useful discussions, as well as Tessa James (Innogenetics, Ghent, Belgium) for editorial assistance. The Vlaams Instituut ter Bevordering van het Wetenschappelijk-Technologisch Onderzoek in de Industrie (IWT) and the Fund for Scientific Research (FWO) supported this research. The Innotest Phospho-Tau 181 assay, which made this study possible, was provided free of charge to BE and PC by Innogenetics nv. EVM and HVDS are employees of the company Innogenetics nv, and assisted not only in the study by supplying the kit and the technical knowhow, but also in the preparation of the manuscript.

\section{Authors' affiliations}

B Van Everbroeck, P Pals, J-J Martin, P Cras, Laboratory of

Neurobiology and Neuropathology, Born Bunge Foundation, University of Antwerp, Wilrijk, Belgium

A J E Green, The National CJD Surveillance Unit, Western Genera Hospital, Edinburgh, UK

E Vanmechelen, H Vanderstichele, Innogenetics NV, Ghent, Belgium R Sanchez-Valle, CJD unit, Hospital Clinic, Villarroel 170, Barcelona, Spain

N Cuadrado Corrales, Department of Applied Epidemiology, National Centre for Epidemiology, Carlos III Institute of Health and Research Brain Bank, Complutesis University, Madrid, Spain

Correspondence to: Dr P Cras, Laboratory of Neurobiology, Born Bunge Foundation, University of Antwerp, Universiteitsplein 1, B-2610 Wilrijk, Belgium; cras@uia.va.ac.be
Received 21 December 2001

In revised form 27 March 2002

Accepted 27 March 2002

\section{REFERENCES}

1 Prusiner SB. Novel proteinaceous infectious particles cause scrapie. Science 1982;216:136-44.

2 Kretzschmar HA, Ironside JW, DeArmond SJ, et al. Diagnostic criteria for sporadic Creutzfeldt-Jakob disease. Arch Neurol 1996;53:913-20.

3 Parchi P, Giese A, Capellari S, et al. Classification of sporadic Creutzfeldt-Jakob disease based on molecular and phenotypic analysis of 300 subjects. Ann Neurol 1999;46:224-33.

4 Hsich G, Kenney K, Gibbs CJ, et al. The 14-3-3 brain protein in cerebrospinal fluid as a marker for transmissible spongiform encephalopathies. N Engl J Med 1996;335:924-30.

5 Otto M, Wiltfang J, Tumani $\mathrm{H}$, et al. Elevated levels of tau-protein in cerebrospinal fluid of patients with Creutzfeldt-Jakob disease.

6 Otto M, Wiltfang J, Cepek L, et al. Tau protein and 14-3-3 protein in the differential diagnosis of Creutzfeldt-Jakob disease. Neurology 2002; 58:192-7.

7 Otto M, Esselmann H, Schulz-Schaeffer W, et al. Decreased beta-amyloid 1-42 in cerebrospinal fluid of patients with Creutzfeldt-Jakob disease. Neurology 2000;54:1099-102.

8 Van Everbroeck B, Green A, Pals P, et al. Decreased levels of amyloid-beta 1-42 in cerebrospinal fluid of Creutzfeldt-Jakob disease patients. J Alzheimers Dis 1999:1:419-24.

9 Green AJE, Thompson EJ, Stewart GE, et al. Use of 14-3-3 and other brain-specific proteins in CSF in the diagnosis of variant Creutzfeldt-Jakob disease. J Neurol Neurosurg Psychiatry 2001;70:744-8

10 Vanmechelen E, Vanderstichele H, Davidsson P, et al. Quantification of tau phosphorylated at threonine 181 in human cerebrospinal fluid: a sandwich ELISA with a synthetic phosphopeptide for standardization. Neurosci lett 2000:285:49-52.

11 McKhann G, Drachmann D, Folstein M, et al. Clinical diagnosis of Alzheimer's disease: report of the NINCDS-ADRDA Work Group unde the auspices of Department of Health and Human Services Task Force on Alzheimer's Disease. Neurology 1984;34:939-44.

12 Vandermeeren $M$, Mercken M, Vanmechelen E, et al. Detection of tau proteins in normal and Alzheimer's disease cerebrospinal fluid with a sensitive sandwich enzyme-linked immunosorbent assay. J Neurochem 1993;61:1828-34.

13 Van Everbroeck B, Pals P, Dziedzic T, et al. Retrospective study of Creutzfeldt-Jakob disease in Belgium: neuropathological findings. Acta Neuropathol 2000:99:358-64.

14 Van Everbroeck B, Croes E, Pals P, et al. Influence of the prion protein and the apoliproprotein $E$ genotype on the Creutzfeldt-Jakob disease phenotype. Neurosci Lett 2001;313:69-72.

15 Reynolds CH, Utton MA, Gibb GM, et al. Stress-activated protein kinase/c-jun N-terminal kinase phosphorylates tau protein. J Neurochem $1997 \cdot 68: 1736-44$

16 Isagawa T, Mukai H, Oishi K, et al. Dual effects of PKNalpha and protein kinase $\mathrm{C}$ on phosphorylation of tau protein by glycogen synthase kinase-3beta. Biochem Biophys Res Commun 2000;273:209-12.

\section{NEUROLOGICAL STAMP}

\section{Constantin von Economo (1876-1931)}

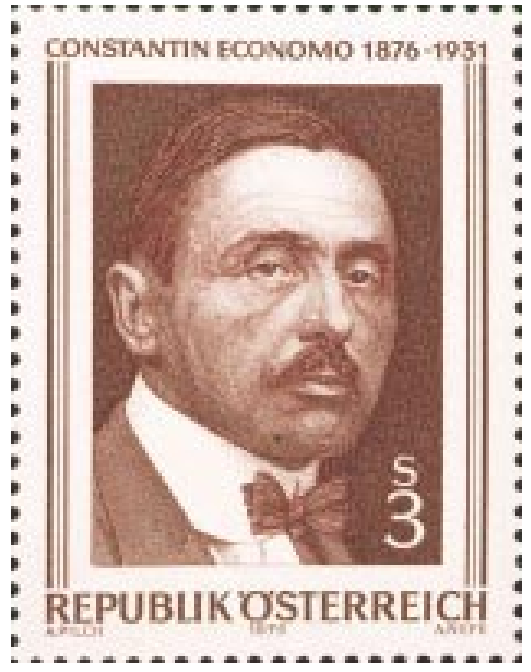

B ron Constantin von Economo was the first Austrian to obtain a pilot's diploma. He served aviation with distinction and supported preparations for the International Aviation Congress held in Vienna. Economo, of Greek parentage, was brought up in Austrian Trieste. He enrolled in engineering school, but after two years began his medical training in Vienna and received his medical degree in 1901. In 1906, Economo became an assistant to Julius Wagner Jauregg, psychiatrist in Vienna. Wagner Jauregg received the Nobel Prize in 1927 for his use of malaria inoculation to induce fever in patients with syphilitic dementia paralytica.

In his early studies, Economo concentrated on the anatomy and physiology of the midbrain, pons, and trigeminal nerve pathway. In 1930 he described (with L Horn) the upper temporal lobe on the left as usually larger than on the right. A major contribution of his was The Cytoarchitecture of the Cerebral Cortex in Adult Man published in 1925 but he is eponymously known for his description of encephalitis lethargica, also known as Von Economo's Disease. ${ }^{1}$ As well as the clinical features, Economo also discussed the pathology and histology. The disease first appeared in Romania in 1915 and raged globally until 1927. Encephalitis lethargica was once a major cause of post-encephalitic Parkinson's Disease, but there have been no new cases for years. The last reported case was in 1940, though the clinical sequelae were seen for years after that.

Economo was a man of independent means. He rejected the chair of psychiatry when von Jauregg retired in 1928. In 1976 on the centenary of Economo's birth a stamp was issued by Austria to honour him. (Stanley Gibbons no. 1765; Scott no. 1040). Austria also philatelically honoured Wagner Jauregg, in 1957 on the centenary of his birth.

L F Haas

1 Pearce JM. Baron Constantin von Economo and encephalitis lethargica. J Neurol Neurosurg Psychiatry 1996;60:167. 